\title{
The Association of Age Groups in Different Settings with Self-Protective Behavior toward COVID-19 in Indonesia: An Online-Cross-sectional study
}

\author{
Raihana Nadra Alkaff ${ }^{*}$, Aisyah Maulina Zjubaidi² ${ }^{2}$ Rr. Arum Ariasih ${ }^{3}$, Dela Aristi $^{4}$, Gina Fauzia ${ }^{5}$, \\ Mustakim $^{6}$ \\ \{raihana.alkaff@uinjkt.ac.id ${ }^{1}$, aisyahmz@gmail.com², rrarumariasih@umj.ac.id ${ }^{3}$, dela.aristi@gmail.com4, \\ ginafauzia87@gmail.com ${ }^{5}$, tqmtentrem108@hotmail.co.id $\}$ \\ *corresponding author
}

Public Health Study Program Faculty of Health Sciences, UIN Syarif Hidayatullah Jakarta, Ciputat, 15419. Indonesia ${ }^{1,4}$

IAKMI Tangerang Selatan, Jalan Pajajaran No.1 Pamulang Kota Tangerang Selatan, 154171,2,3,4,5,6,

Universitas Muhammadiyah Jakarta, K.H. Ahmad Dahlan, Cirendeu, Ciputat, Tangerang Selatan 3,6

\begin{abstract}
There is a need to think of the best strategies to get the message across by redesigning health messages of self-protective behaviors toward COVID-19. The aim of the study was to identify the association of age groups in different settings with self-protective behavior. An online cross-sectional survey was conducted between July and August 2020. A convenience sample of 440 respondents in Tangerang Selatan city was collected. The chisquare test was used for age comparisons. The results showed that the main self-protective behavior of wearing masks, maintaining physical distancing and washing hands ranged from $79.5 \%$ to $98.6 \%, 66.7 \%$ to $79.2 \%$, and $63.2 \%$ to $67.2 \%$ respectively. Significantly, young people were 7.7 times more likely to wear masks than adults in convenience stores. The findings suggest that there may be an important indicator of effective messaging in different settings, especially to support people to adopt and maintain these behaviors in the future.
\end{abstract}

Keywords: COVID-19; Masks; Physical distancing; Washing hand; Self-protective behavior.

\section{Introduction}

On January 30, 2020, the World Health Organization (WHO) declared the COVID-19 outbreak as a global pandemic due to its severity and rapid spread across six continents which have reached almost every country in the world. The latest condition of COVID-19 cases in the world, based on official WHO data on mid-August 2020, reported that more than 20 million confirmed cases of COVID-19, with around 750.000 deaths [1]. COVID-19 is an infectious disease caused by a new type of Coronavirus, namely SARS-CoV-2, with general symptoms, such as fever, fatigue, dry cough, and experiencing pain and sore throat, which are experienced continuously and appear 
gradually. The uniqueness of COVID-19 is that people with COVID-19 can be asymptomatic but still infectious, this is why the transmission of COVID-19 cannot be easily controlled.

The Director General of WHO, Tedros A. Ghebreyesus, on July 132020 stated that there are three epidemic control measures at present and in the future, namely 1) Focus on reducing mortality and reducing transmission, 2) Communities who are empowered and involved in taking individual behavioral (self-protection) measures for the benefit of each other, and 3) strong government leadership and coordinated comprehensive strategies that are clearly and consistently communicated [2]. Creating the strategy to encourage people to adopt self-protective behavior against COVID-19 is now becoming crucial. The need for the implementation of public health efforts in increasing knowledge, attitudes and behavioral skills for self-protection against COVID-19 are a major public health problem that currently must be prioritized by the government in dealing with COVID-19 [3].

One way to encourage community adoption of new behaviors is to understand the factors that influence self-protection behavior towards COVID-19. A study found that factors associated with self-protecting behavior during the COVID-19 pandemic were income, work arrangements, space at home, region, gender and beliefs [4]. Meanwhile, other studies revealed that sex, age, ethnicity, marital status and employment status were also associated preventive behaviors $[5,6]$. Those studies suggested that public health policies that consider those associated factors are likely to be effective or sustainable [4-6].

The Indonesian government, both at the central and regional (district/city) levels, issued policies on the Application of Large-Scale Social Restrictions (Penerapan Pembatasan Sosial Berskala Besar/PSBB) to create conducive conditions to support the accelerated adoption of selfprotective behavior towards COVID-19 in breaking the chain of transmission in various regions. This policy is expected to encourage increased self-protection behavior at both individual and community levels. As of September 14, 2020, 86\% of Indonesian respondents stated that they were wearing face masks when in public places during the COVID-19 outbreak, up from $54 \%$ on February 24,2020 [7]. UNICEF Indonesia reported that the rate of hand-washing at $37 \%$, mask use at $74 \%$ and safe-distancing at $63 \%$ nationally [8].

Redesigning policy in health messages is expected to support the accelerated adoption of self-protective behavior towards COVID-19 in breaking the chain of transmission. A study revealed that self-protective behavior declines with increasing age [6]. Although the patterns of selfprotective behavior in general were studied, self-protective behavior among age group in many settings was unknown. One of Japan's COVID-19 control policies is to determine priority cluster investigations through priority setting approaches [9]. High priority settings consist of hospitals or long-term care facilities, evening entertainment (especially host and hostess clubs) and large social gatherings (parties, theater, live music events) and low / medium priority settings are schools, universities / colleges and work place [9]. In our perspective's settings were important to consider in term of the self-protective behavior. Therefore, the aim of the study was to identify the association of age groups in different settings with self-protective behavior towards COVID-19. 


\section{Method}

\section{Design}

The design of this study used a cross sectional study using an internet-based research approach with a rapid survey method. This research was conducted in South Tangerang City, Banten Province. This research is part of an online self-protective behavior survey research against COVID19 which specifically examines knowledge, attitudes, behavior, and information sources longitudinally which lasts for 6 months, from July to December 2020.

The population in this study were all people who live, study or work in South Tangerang City. The sample size uses a non-random sampling approach using quota sampling per cluster. South Tangerang City consists of 7 districts and 54 villages. The minimum sample set per village is 5 respondents. The total sample is expected to be at least 270 respondents.

The data was collected using a questionnaire in a google form platform which was accessed online by the respondents. Respondents received links that were shared by the research team via social media networks and email or personal email. The research team mobilized the general public snowballing through social media Facebook, Twitter, Instagram, WhatsApp and email. Data collection was carried out for 14 days on 24 July 2020 to 8 August 2020.

Before filling out the online questionnaire, respondents were asked their willingness to voluntarily understand informed consent and agree to it. If they agree, the respondent will state their willingness by pressing the agree button and next button in the survey questionnaire. The ethics of this research have been approved by the Ethics Commission of the Faculty of Health Sciences Syarif Hidayatullah State Islamic University Jakarta (No.Un.01/F.10/KP.01.1/KE.SP/07.08.19/2020).

\section{Survey}

The questionnaire consists of several subsections, namely informed consent, sociodemographics, behavior, attitudes, subjective norms, perceptions of behavior control and intention. Measurement results for behavioral questions using 4 scales (Yes, only if necessary / occasional, No and Don't know) adapted from research by Daoust et.al.2020 which recommends a measuring scale in order to minimize bias in measuring adherence to self-protective behavior against COVID-19 [10]. We define self-protective behavior as an act of protecting oneself from COVID-19 which mainly consists of wearing a mask, maintaining physical distancing and washing hands. The five settings in the study consist of traditional markets, malls/ supermarkets, mini markets, places of worship and public facilities.

\section{Data Analysis}

Data is transferred from google form to Microsoft Excel which is then transferred to statistical software. The significance level of $\alpha$ was considered 0.05 in all tests. The normality of the data was tested by the Kolmogorov Smirnov test. Descriptive statistics were performed to explore the means, median, standard deviation (SD) and prevalence (\%) for categorical variables. Then, the chi-square test was used for age comparisons. In this research we divided age groups into young people (below 25-year-old) and adults (25 years old and above) to know the differences between two groups [11]. All analysis conducted through SPSS software (version 24; SPSS Inc., Chicago, IL, USA). 


\section{Result}

A total of 450 questionnaires were collected via Google Form. Out of 450 respondents, 442 (98.2\%) agreed to participate in the study. Meanwhile, there were 2 respondents who did not complete the questionnaire. Thus, 440 respondents were included for the analyses. The proportion of female was higher than male (76.6\% vs. $23.4 \%)$.

Table 1. Characteristics of respondents by settings

\begin{tabular}{|c|c|c|c|c|c|c|c|c|c|c|}
\hline \multirow[t]{2}{*}{ Variable } & \multicolumn{2}{|c|}{$\begin{array}{c}\text { Traditional } \\
\text { Market } \\
\mathbf{n}=102 *\end{array}$} & \multicolumn{2}{|c|}{$\begin{array}{c}\text { Mall/ } \\
\text { Supermarket } \\
\mathbf{n}=\mathbf{2 1 2} *\end{array}$} & \multicolumn{2}{|c|}{$\begin{array}{c}\text { Convenience } \\
\text { Store } \\
\mathbf{n}=\mathbf{2 3 3} *\end{array}$} & \multicolumn{2}{|c|}{$\begin{array}{c}\text { The Place of } \\
\text { Worship } \\
\mathbf{n}=117 *\end{array}$} & \multicolumn{2}{|c|}{$\begin{array}{c}\text { Public } \\
\text { Facilities } \\
\mathbf{n}=125 *\end{array}$} \\
\hline & f & $\%$ & f & $\%$ & f & $\%$ & f & $\%$ & $\mathbf{f}$ & $\%$ \\
\hline \multicolumn{11}{|l|}{ Age } \\
\hline$<25$ years old & 65 & 63.7 & 149 & 70.3 & 127 & 54.5 & 76 & 65.0 & 87 & 69.6 \\
\hline$>=25$ years old & 37 & 36.3 & 63 & 29.7 & 106 & 45.5 & 41 & 35.0 & 38 & 30.4 \\
\hline \multicolumn{11}{|l|}{ Education level } \\
\hline Primary to secondary & 49 & 48.0 & 4 & 1.9 & 7 & 3.0 & 1 & 0.9 & 1 & 0.8 \\
\hline Higher than secondary & 54 & 52.0 & 208 & 98.1 & 226 & 97.0 & 116 & 99.1 & 124 & 99.2 \\
\hline \multicolumn{11}{|l|}{ Occupation } \\
\hline Not working & 31 & 30.4 & 78 & 36.8 & 68 & 29.2 & 40 & 34.2 & 40 & 32.0 \\
\hline Working & 71 & 69.6 & 134 & 63.2 & 165 & 70.8 & 77 & 65.8 & 85 & 68.0 \\
\hline
\end{tabular}

$*_{n}$ is the total number of respondents who visited the setting in the past one week. One respondent could visit more than two settings.

The results on Table 1 showed that respondents aged $<25$ years old tend to visit places such as traditional markets $63.7 \%$, malls or supermarkets $70.3 \%$, mini markets $54.5 \%$, houses of worship $65 \%$ and public facilities $69.6 \%$ compared to respondents aged $>=25$ years old at the time of PSBB. Other results show that respondents with higher than secondary education tend to visit places such as traditional markets $52 \%$, malls or supermarkets $98.1 \%$, mini markets $97 \%$, houses of worship $99.1 \%$ and public facilities $99.2 \%$ compared to respondents who had low education at the time of PSBB. Furthermore, based on job characteristics, respondents who work tend to visit places such as traditional markets $69.6 \%$, malls or supermarkets $63.2 \%$, convenience stores $70.8 \%$, houses of worship $65.8 \%$ and public facilities $68 \%$ compared to respondents did not work during the PSBB. 
Table 2. The percentage of Self-protective behavior by settings

\begin{tabular}{llrrrrrr}
\hline & & Wearing & \multicolumn{2}{c}{$\begin{array}{c}\text { Self-Protective Behavior } \\
\text { Maintaining } \\
\text { Physical } \\
\text { Distancing } \\
\text { No }\end{array}$} & \multicolumn{1}{c}{ Settings } & fasks & \multicolumn{2}{c}{$\begin{array}{c}\text { Washing } \\
\text { Hands }\end{array}$} \\
& & f & \% & f & f & \% \\
\hline 1 & Traditional market & 99 & 97.1 & 71 & 69.6 & 68 & 66.7 \\
2 & Mall/ Supermarket & 209 & 98.6 & 168 & 79.2 & 135 & 63.7 \\
3 & Mini market & 223 & 95.7 & 191 & 82.0 & 151 & 64.8 \\
4 & Places of worship & 93 & 79.5 & 78 & 66.7 & 74 & 63.2 \\
5 & Public facilities & 120 & 96.0 & 93 & 74.4 & 84 & 67.2 \\
\hline
\end{tabular}

In general, as seen on Table 2 , more than $60 \%$ of young and adults respondents have done self-protecting behavior (wearing masks, maintaining physical distancing and washing hands) in these five settings. The results showed that the main self-protective behavior of wearing masks, maintaining physical distancing and washing hands ranged from $79.5 \%$ to $98.6 \%, 66.7 \%$ to $79.2 \%$, and $63.2 \%$ to $67.2 \%$ respectively. Convenience stores were the places most visited by respondents compared to other settings in this study at the time of the PSBB. Meanwhile, places of worship were the setting least visited by respondents.

Table 3. Association between age groups in different settings and self-protective behavior (wearing masks, maintaining physical distancing and washing hand)

\begin{tabular}{|c|c|c|c|c|c|c|c|c|}
\hline \multirow{3}{*}{ No } & \multirow{3}{*}{ Setting } & \multicolumn{4}{|c|}{ Wearing Masks } & \multirow{3}{*}{ Total } & \multirow{3}{*}{$\begin{array}{c}\text { POR } \\
(95 \% \text { CI })\end{array}$} & \multirow{3}{*}{$P$ value } \\
\hline & & \multicolumn{2}{|c|}{ Yes } & \multicolumn{2}{|c|}{ No } & & & \\
\hline & & $\mathrm{f}$ & $\%$ & $\mathrm{f}$ & $\%$ & & & \\
\hline \multirow[t]{3}{*}{1} & Traditional Market & & & & & & & \\
\hline & $>=25$ years old & 36 & 97.3 & 1 & 2.7 & 37 & 1.14 & \\
\hline & $<25$ years old & 63 & 96.9 & 2 & 3.1 & 65 & $(0.10-13.04)$ & 0.703 \\
\hline \multirow[t]{3}{*}{2} & Mall/Supermarket & & & & & & & \\
\hline & $>=25$ years old & 62 & 98.4 & 1 & 1.6 & 63 & 0.84 & 1.000 \\
\hline & $<25$ years old & 147 & 98.7 & 2 & 1.3 & 149 & $(0.08-9.47)$ & \\
\hline \multirow[t]{3}{*}{3} & Convenience stores & & & & & & & \\
\hline & $>=25$ years old & 104 & 99.0 & 1 & 1.0 & 105 & 7.93 & $0.020 *$ \\
\hline & $<25$ years old & 119 & 92.9 & 9 & 7.1 & 128 & $(0.98-63.67)$ & \\
\hline \multirow[t]{3}{*}{4} & The place of worship & & & & & & & \\
\hline & $>=25$ years old & 33 & 80.5 & 8 & 19.5 & 41 & 1.10 & 1.000 \\
\hline & $<25$ years old & 60 & 78.9 & 16 & 21.1 & 76 & $(0.43-2.82)$ & \\
\hline \multirow[t]{2}{*}{5} & Public Facilities & & & & & & & \\
\hline & $>=25$ years old & 37 & 97.4 & 1 & 2.6 & 38 & 1.78 & 0.518 \\
\hline
\end{tabular}




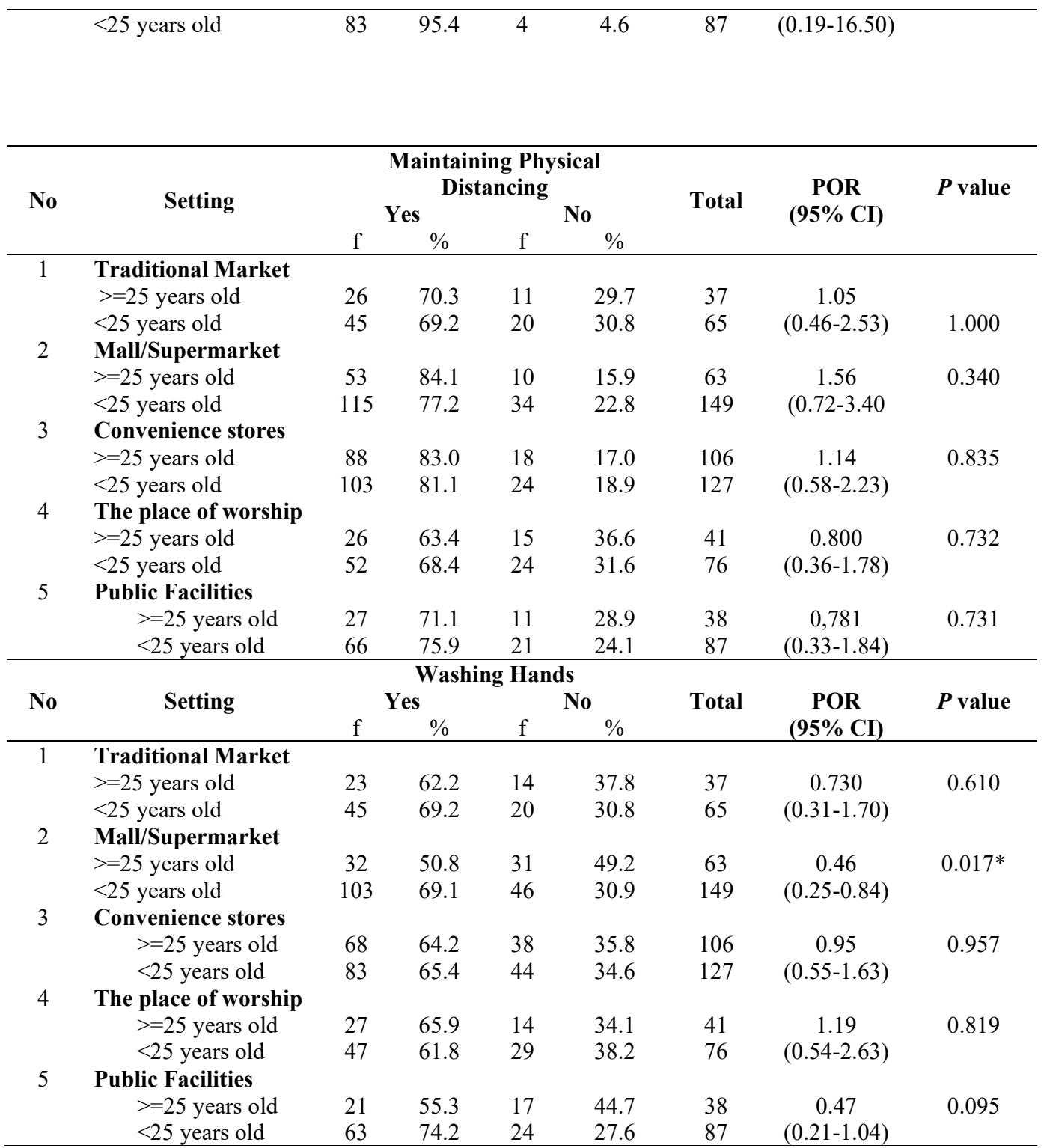

$* p$ value $<0.05$

Respondents mostly choose wearing masks compared to physical distancing and washing hands. Both youth and adults seem to prefer wearing masks over other behaviors. The lowest behavior of wearing both youth and adult masks occurred in the place of worship. Most youth and adults have done physical distancing in various settings. Traditional markets and houses of worship 
are settings where this behavior is less prevalent than market settings, malls and convenience stores. Even though most respondents (around 60\%) had washed their hands while in the five settings, this behavior was the least used by respondents to protect themselves from COVID-19 transmission. The pattern of self-protecting behavior in the setting of markets, malls, places of worship and public facilities in the two age groups did not show a significant difference. However, there are interesting findings, first, young people were 7.7 times more likely to wear masks than adults in convenience stores. Second, young people 0.46 times less likely to do hand-washing compare to Adults in supermarkets/malls or in other words, adults were 2.1 times $(1 / 0.46=2.1)$ more likely to do handwashing than young people in supermarkets/malls.

\section{Discussion}

This study has some limitations, respondents in this study were recruited non-randomly through social media networks, which selectively can only be accessed mostly by groups who actively access the media. In this study, the participation of women is more than that of men, so we do not know whether this can lead to different results. It reflects that this study can only provide an analysis of the behavior in accordance with the characteristics that exist in the study sample, it cannot be generalized to populations with different characteristics. This study only presented three main self-protection behaviors in five settings which are insufficient to describe the overall self-protective behavior of the community. When interpreting this study, we must take those limitations into the account.

This study found that adults are less likely to wear masks than young people in convenience stores. It is in line with the study in Portugal, self-protective behavior declines with increasing age [6]. In contrast, study in the United States revealed that compared with younger people, older people reported more frequent to do self-protective behavior [5]. Although it still needs further investigation, our finding is quite interesting to analyze. It is possible that the adult's unawareness is due to the short time duration that they spent visiting the setting. It is also possible that adults has lower perceived risk compare to young people [6].

Interestingly, this study found that the proportion of people who hand-washing in supermarket/malls is 2.1 fold greater if a person is adult. Our result is similar with other study that highlighted that older people more frequent efforts to wash-hands compare with younger people [5]. It may be supported by the perception of susceptibility in adults so that they wash their hands more frequently, although this study was not investigated the perceived of susceptibility among both groups.

Our main findings suggested that there is a tendency that changing a setting will also change a person's self-protective behavior in different age group. People in different age group will consider to engage self-protective behavior while they were in a certain setting. In general, young people have higher perceived risk since they face anxiety and fear of death compare to adult which results the increasing of their self-protective behaviors [6]. It is possible that perceived risk will decrease when young people visit settings that they familiar with such as supermarket/malls. A study mentioned that the impact of atmosphere in mall on self-congruity was significant for young people [12]. Lack of awareness in young people in mall/supermarket will affect their high-perceived risk 
that they have in other settings. As well as young people, the adults also have lack of awareness in the convenience stores with the same reason.

In general, the results of this study indicate that the most self-protective behavior is using masks, while washing hands is the least practiced behavior. Although the use of masks is important, it is not accompanied by hand washing and physical distancing. In line with our study, other studies founded similar behavior patterns $[4,5,8,13]$. It suggests that there are need more attention to improve hand washing behavior and maintaining distance. A person's intention to behave greatly influences by other person point of view [14]. Additionally, in addition to cultural factors also determine on how new behavior can be adopted quickly. According to a study conducted by UNICEF, maintaining distance is the most difficult behavior for Indonesians [8]. It is because there is a concern that they will perceive as an arrogant person and avoid social connectivity when they keep their distance [8]. A study found that an important resource for adherence to the keeping 1.5 $\mathrm{m}$ physical distance measure was social support [15].

Lessons learned from the strategy undertaken by Japan which focuses more on physical distancing by packaging messages to the public to avoid the "three Cs" - closed spaces, crowds, and close-contact settings in which people are talking face-to-face [16]. This strategy was quite effective in getting Japan to deal with the pandemic in the country. The thing that needs to be underlined is that the message is in accordance with Japanese culture which is accustomed to wearing masks outside the home and frequently washing hands [16,17]. Every country has different social contexts, objectives, and goals, things that need to be considered for a country like Indonesia with different cultures is how pack the message "physical distancing" more easily and reach the public.

The findings in this study suggest that the age group in different settings may be an important variable in developing an effective message strategy. Developing health messages is not only aimed at increasing knowledge but also how to invite people to adopt the suggested health behavior. WHO pointed out that factors to consider when prioritizing channels include their reach (number of people that will hear, see, or read a message), and how the channel supports audiences' ability to recall the message and impact (whether the message results in action) [18]. A lack in people's self-protection and ignorance toward policies is the result of the decision making in governance which is not considered by the audience perceptions and concerns [19]. In delivering health messages, the methods used during the pandemic are more indirect methods thru internet-based media such as websites or social media. The role of internet-based media has become more intense since the outbreak of the pandemic as a source of information related to COVID-19, such as the information of the disease, morbidity and mortality as well as information related to prevention and treatment. Therefore, in developing health messages through internet-based media, we need to consider which are most suited to population segments.

Hence, delivering health messages through familiar sources has an effect on motivation to take action and change behavior [20,21]. Message content must also take into account the elements of rationality and empathy in accordance with the recommendations of a study of cross-cultural found that rationality and empathy were positive predictors of decisions to wear a mask [22]. To increase empathy, the message contains a description of the potential number of infections that can occur if a person does not wear a mask and the losses that can occur. In addition, packaging messages using "info-graphics" so that they are easier to understand. The message could also contain agerelated vulnerability to contracting COVID-19. Data can also be added with information on the 
number of infection cases in the area. The more information is packaged locally, the easier it is to understand.

\section{Conclusion}

This study shows that setting and age group influence the increase in self-protective behavior. People in different age groups will consider engaging in self-protective behavior when they are in certain environments. The findings suggest that there may be important indicators of effective messaging in different settings, especially to support people to adopt and maintain the continuity of these behaviors in the future

Competing interests. The authors declare that they have no competing interests

Acknowledgments. We would like to thank the field team for their valuable work; and Fatin and Nindy for helping us to transfer data from google form to SPSS data. First author expresses gratitude to Ikatan Ahli Kesehatan Masyarakat Tangerang Selatan (IAKMI Tangsel) for supporting this research.

\section{References}

[1] WHO. Coronavirus disease (COVID-2019) situation reports. 2020 [cited 202016 July]; Available from: https://www.who.int/emergencies/diseases/novel-coronavirus-2019/situation-reports (2020)

[2] WHO. WHO Director-General's opening remarks at the media briefing on COVID-19 - 13 July 2020. 2020 [cited 202014 July]; Available from: URL: .https:/www.who.int/dg/speeches/detail/whodirector-general-s-opening-remarks-at-the-media-briefing-on-covid-19---13-july-2020.(2020)

[3] Peeradone, S., et al., Knowledge, attitudes and preparedness to respond to COVID-19 among the border population of northern Thailand in the early period of the pandemic: a crosssectional study. WHO South-East Asia Journal of Public Health, 2020. 9(2): p. 118-125. (2020)

[4] Papageorge, N.W., et al., Socio-Demographic Factors Associated with Self-Protecting Behavior during the COVID-19 Pandemic. 2020, Institute of Labor Economics (IZA).

[5] Li, S., et al., Internet Use, Risk Awareness, and Demographic Characteristics Associated With Engagement in Preventive Behaviors and Testing: Cross-Sectional Survey on COVID-19 in the United States. J Med Internet Res, 2020. 22(6): p. e19782.(2020)

[6] Pasion, R., et al., The AGE Effect on Protective Behaviors During the COVID-19 Outbreak: Sociodemographic, Perceptions and Psychological Accounts. Frontiers in Psychology, 2020. 11(2785). (2020)

[7] Hirschmaan, R., Respondents who wore masks in public COVID-19 outbreak Indonesia, 2020. (2020)

[8] UNICEF, Indonesia COVID-19 Response Situation Report on October, 12, 2020. (2020)

[9] Oshitani, H., The retrospective tracing methodology, how it was developed, and how it has been implemented in Japan., in A Conversation with experts on how US States can implement retrospective contact tracing, r.B.K.C.f.I.S.a.H. University, Editor. 2020: USA. (2020) 
[10] Daoust, J.-F., et al., How to Survey Citizens' Compliance with COVID-19 Public Health Measures: Evidence from Three Survey Experiments. Journal of Experimental Political Science, 2020: p. 1-8. (2020)

[11] Sawyer, S.M., et al., Adolescence: a foundation for future health. The Lancet, 2012. 379(9826): p. 1630-1640. (2012)

[12] Massicotte, M.-C., et al., Effects of mall atmosphere on mall evaluation: Teenage versus adult shoppers. Journal of Retailing and Consumer Services, 2011. 18(1): p. 74-80. (2011)

[13] BPS, Perilaku Masyarakat di masa pandemik. Hasil Survei Perilaku Masyarakat di Masa Pandemi COVID-19 (7-14 September 2020) in Bahasa. (2020)

[14] Ajzen, I., Attitudes Personality And Behavior. 2005: McGraw-Hill Education, U.K. (2005)

[15] Beeckman, M., et al., Adherence to the Physical Distancing Measures during the COVID-19 Pandemic: A HAPA-Based Perspective. Applied Psychology: Health and Well-Being, 2020. (2020)

[16] Tashiro, A.S., R., Pandemic Response in Japan: What Is behind the Initial Flattening of the Curve? Sustainability 2020, 12, 5250. Sustainability 2020. 12(5250).(2020)

[17] Burgess, A. and M. Horii, Risk, ritual and health responsibilisation: Japan's 'safety blanket' of surgical face mask-wearing. Sociology of Health \& Illness, 2012. 34(8): p. 1184-1198. (2012)

[18] WHO, WHO Strategic Communications Framework for Effective Communications. (2017)

[19] Zhang, L., H. Li, and K. Chen, Effective Risk Communication for Public Health Emergency: Reflection on the COVID-19 (2019-nCoV) Outbreak in Wuhan, China. Healthcare (Basel, Switzerland), 2020. 8(1): p. 64. (2020)

[20] Aldoory, L., et al., Piloting Health Text Messages for Rural Low-Income Mothers: Effects of Source Similarity and Simple Action Steps. Health Promot Pract, 2016. 17(5): p. 702-10. (2016)

[21] WHO, R.O.f.t.E.M., Health education: theoretical concepts, effective strategies and core competencies: a foundation document to guide capacity development of health educators. (2012)

[22] Zirenko, M., et al., Personality regulation of decisions on physical distancing: Cross-cultural comparison (Russia, Azerbaijan, China). Personality and Individual Differences. 170: p. 110418. (2020) 